\title{
Poplar agroforestry systems in eastern China enhance the spatiotemporal stability of soil microbial community structure and metabolism
}

\author{
Bo Wang ${ }^{1}$, Ling Zhu ${ }^{2}$, Tao Yang ${ }^{1}$, Zhuangzhuang Qian ${ }^{1}$, Cheng Xu ${ }^{1}$, Di $\operatorname{Tian}^{1}$, and \\ Luozhong Tang ${ }^{1}$ \\ ${ }^{1}$ Nanjing Forestry University \\ ${ }^{2}$ Shigatse Vocational Technical School
}

November 6, 2021

\begin{abstract}
Agroforestry systems provide soil microorganisms with a rich variety of carbon sources and a relatively stable living environment. In this study, five planting systems were investigated; a pure poplar (Populus $\times$ euramericana 'Nanlin 895') plantation (P) system, a pure crop (wheat [Triticum aestivum L.] and soybean [Glycine max (Linn.) Merr.]) (WS) system, a poplar + wheat + soybean agroforestry (PWS) system, a poplar + potherb mustard (Brassica juncea var. multiceps) agroforestry (PP) system, and a poplar + native chicken agroforestry $(\mathrm{PN})$ system. The Biolog EcoPlate method was used to determine the vertical and seasonal variations in soil microbial metabolic capacity. The average well color development, carbon source utilization ability, and microbial diversity index values were higher throughout the soil profile, and highly stable with seasonal changes in the PWS and PP agroforestry systems. Furthermore, the influence of the planting systems and seasonal changes on the metabolic activity of soil microorganisms decreased with an increase in soil depth. Overbreeding chickens in the forest reduced the metabolic activity of soil microorganisms. It was also found that plants influenced soil microbial metabolism through the available carbon source types. Therefore, agroforestry systems improved the metabolic potential of the soil microbial community. Our results demonstrated that soil microbial communities are affected by the planting system and soil depth. The findings enhance our understanding of the functional diversity of soil microorganisms in agroforestry systems.
\end{abstract}

\section{Hosted file}

manuscript.doc available at https://authorea.com/users/444806/articles/544459-poplaragroforestry-systems-in-eastern-china-enhance-the-spatiotemporal-stability-of-soilmicrobial-community-structure-and-metabolism 